\title{
Dielectric characteristics of GaSe nanocrystals intercalated with hydrogen
}

\author{
V.M. Kaminskii, Z.D. Kovalyuk, V.V. Netyaga, and V.B. Boledzyuk \\ I.M. Frantsevich Institute for Problems of Materials Science, NAS of Ukraine, Chernivtsi Department \\ 5, Iryna Vilde str., 58001 Chernivtsi, Ukraine; e-mail: chimsp@ukrpost.ua
}

\begin{abstract}
The results of investigations of dielectric characteristics of GaSe nanocrystals and their hydrogen intercalates are presented. By using the impedance spectroscopy method, it is established that the dielectric spectra of GaSe and $\mathrm{H}_{\mathrm{x}} \mathrm{GaSe}(\mathrm{x}=0.07$ and 0.14 ) nanocrystals correspond to the exponent law of dielectric response. It is found that there is an increase of the dielectric constant $\varepsilon_{\infty}$ for the intercalated samples in comparison with that of the initial sample. We have obtained the frequency dependences of the real and imaginary parts of the conductivity, whose dispersion is due to the presence of two-dimensional defects. Equivalent electrical circuits which determine electrical characteristics of the crystals under study are proposed.
\end{abstract}

Keywords: gallium selenide, nanocrystal, intercalation, impedance spectroscopy, dielectric characteristics.

Manuscript received 15.09.07; accepted for publication 27.09.07; published online 30.11.07.

\section{Introduction}

The anisotropy of physical properties of layered III-VI semiconductors is caused by peculiarities of their crystal structure and can be essentially increased when they are in a form of nanocrystals, as well as due to topochemical reactions of intercalation (the insertion of foreign atoms into the interlayer spaces). The insertion of hydrogen into the lattice of layered materials makes it possible to apply intercalation systems for the preparation of hydrogen-containing materials with high hydrogen content, hydrogen sensors, and solid electrolytes with high proton conductivity $[1,2]$.

Earlier, the electrical and optical properties of hydrogen-containing GaSe and InSe crystals were investigated in [3-5]. In this work, we present the result of investigations of dielectric characteristics of $\mathrm{GaSe}$ nanocrystals intercalated with hydrogen.

\section{Experimental}

Single crystals of GaSe were grown by the Bridgman method from a stoichiometric melt. By using the Weissenberg method, it is found that the grown GaSe crystals belong to the $\varepsilon$-modification (space group $D_{3 h}^{1}$ ).

Nanopowders of GaSe were obtained by means of the ultrasonic treatment of micron-sized powders (a grain dimension of about $75 \mu \mathrm{m}$ ) in a liquid medium (acetone or ethyl alcohol) under cavitation conditions. From the $\mathrm{X}$-ray data, it is established that the average dimensions of the obtained nanoparticles are 70 to $75 \mathrm{~nm}$ along the crystallographic direction [001] [6]. The obtained nanoparticles were pressed at a pressure of $10^{7} \mathrm{~Pa}$ into disks of $9 \mathrm{~mm}$ in diameter and $2.3 \mathrm{~mm}$ in thickness destined for further investigations.

Intercalation of GaSe nanopowders with hydrogen has been carried out by the method of "drawing" electrical field from a $0.1 \mathrm{~N}$ aqueous solution of $\mathrm{HCl}$ at potentials that are below the potential of hydrogen reduction from this solution $(\varphi=0.36 \mathrm{~V}$ with respect to $\mathrm{AgCl}$ electrode). The density of inserted protons was determined from the amount of charge carried out through an intercalation cell by measuring the current density and the intercalation time [7].

Room-temperature impedance spectra were measured by means of an impedance spectrometer "Solartron 1255 " in the frequency range 0.1 to $10^{6} \mathrm{~Hz}$ at an applied signal of $100 \mathrm{mV}$.

\section{Results and discussion}

Figure 1 shows the measured frequency dependences of complex capacitance $C^{*}=C^{\prime}-j C^{\prime \prime}$ for nanocrystalline samples of $\mathrm{GaSe}, \mathrm{H}_{0.07} \mathrm{GaSe}$, and $\mathrm{H}_{0.14} \mathrm{GaSe}$. It was established in [8] that the dielectric spectrum of lowresistance GaSe single crystals correspond to the universal exponential law 


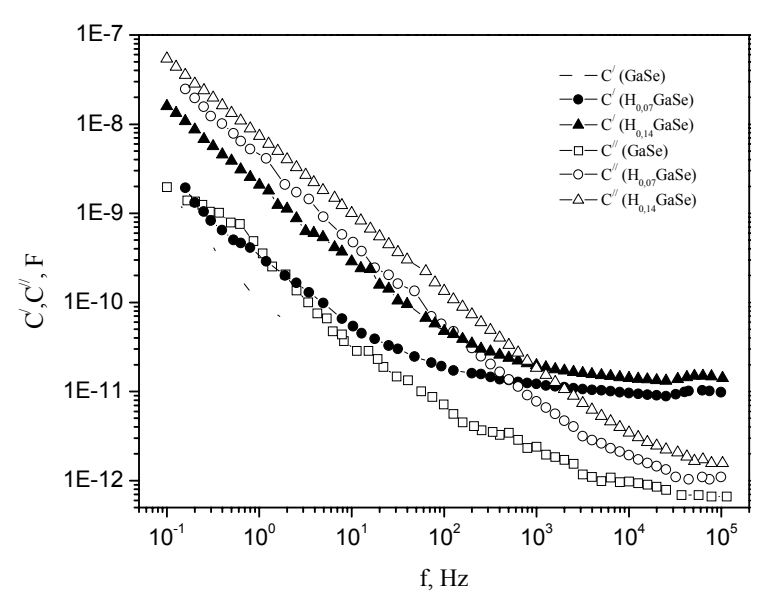

Fig. 1. Dielectric spectra expressed in the form of complex capacitance for nanocrystals of $\mathrm{GaSe}, \mathrm{H}_{0.07} \mathrm{GaSe}$, and $\mathrm{H}_{0.14} \mathrm{GaSe}$.

$$
C^{*}=B(j \omega)^{n-1}=B\left\{\sin \frac{n \pi}{2}-j \cos \frac{n \pi}{2}\right\} \omega^{n-1},
$$

where $0<n<1$ and $B$ is a constant.

As one can see from the presented data for GaSe, $\mathrm{H}_{0.07} \mathrm{GaSe}$, and $\mathrm{H}_{0.14} \mathrm{GaSe}$ nanocrystals under investigations (Fig. 1), the frequency dependences of $C^{\prime}$ and $C^{\prime \prime}$ can be also described by the exponential law at $0<$ $n<1$. For the $C^{\prime}(v)$ dependences in the high-frequency spectral range, there are linear parts with the slope angle tangent equal to zero, the linear cuts off of which at the ordinate axis correspond to the high-frequency capacitance $C_{\infty}^{\prime}$. Using the obtained $C_{\infty}^{\prime}$ values, we have established the comparative increase of the highfrequency permittivity $\varepsilon_{\infty}$ for the intercalated samples in comparison with that of the initial GaSe sample which is equal to 1.02 and 1.51 for the $\mathrm{H}_{0.07} \mathrm{GaSe}$ and $\mathrm{H}_{0.14} \mathrm{GaSe}$ samples, respectively. This takes place because of changes in the polarization processes in the intercalated materials. At low frequencies, the $C^{\prime \prime}(v)$ dependences have the linear parts with the slope angle tangent equal to -1 what is due to the dc conductivity of the samples.

Figure 2 shows the Nyquist plots for the investigated nanomaterials. The presence of deformed semicircles in the high-frequency range (curves 2 and 3 ) is their peculiarity for the intercalated $\mathrm{H}_{0.07} \mathrm{GaSe}$ and $\mathrm{H}_{0.14} \mathrm{GaSe}$ samples. From the obtained data, we have established the electrical equivalent circuits of the investigated samples (Fig. 2, inserts $b$ and $c$ ) and the

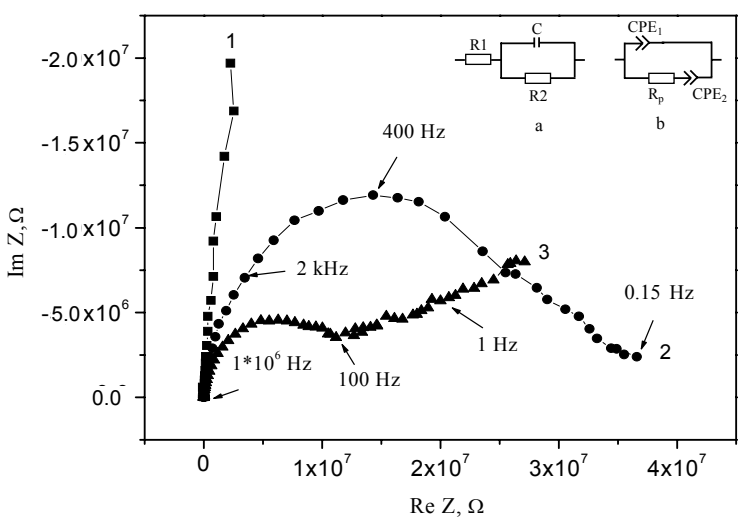

Fig. 2. Nyquist plots for samples of $\mathrm{GaSe}, \mathrm{H}_{0.07} \mathrm{GaSe}$, and $\mathrm{H}_{0.14} \mathrm{GaSe}$ (curves 1 to 3 , respectively) and equivalent circuits for the initial GaSe (insert $a$ ) and its intercalates (insert $b$ ).

parameters of their elements (Table). Here, $\mathrm{CPE}_{1}$ and $\mathrm{CPE}_{2}$ are constant phase elements being used in equivalent circuits. This allows us to describe the deformed semicircles at the Nyquist plots (Fig. 2, curves 2 and 3) for the samples under investigation. The parameters $Y_{1}$ and $Y_{2}$, as well as $n_{1}$ and $n_{2}$, determine numerical values and the behavior type (resistive or capacitive) of the $\mathrm{CPE}_{1}$ and $\mathrm{CPE}_{2}$ elements, respectively. The parameter $C_{\delta}$ is the geometrical capacitance of the investigated sample. As follows from the listed data, the effective capacitance $Y_{1}$ of the $\mathrm{CPE}_{1}$ element for the $\mathrm{H}_{0.14} \mathrm{GaSe}$ sample is increased by several orders of magnitude in comparison with that of $\mathrm{H}_{0.07} \mathrm{GaSe}$, and simultaneously the resistance $R_{p}$ becomes essentially decreased (by $10^{8}$ times). On the contrary, the parameter $Y_{2}$ decreases with increase in the density of inserted hydrogen. This indicates that the circuit $\left(\mathrm{CPE}_{1}\left(R_{p}-\mathrm{CPE}_{2}\right)\right)$ determines the "bulk" electrical properties of porous nanopowdered $\mathrm{H}_{\mathrm{x}}$ GaSe samples.

The availability of a weak van der Waals bonding between the layers of GaSe and a strong ionic-covalent bonding within them foreordains the possibility of the insertion of protons into tetrahedral and octahedral sites of the interlayer spaces. According to the law of hexagonal close packing [9], one octahedral and two tetrahedral empty sites correspond to each atom of Se. Additionally, as distinct from GaSe single crystals, the intercalated samples can localize hydrogen in pores.

Table. Parameters of equivalent circuits for nanocrystalline GaSe samples and their hydrogen intercalates.

\begin{tabular}{|c|c|c|c|c|c|c|c|c|}
\hline & \multicolumn{2}{|c|}{$\mathrm{CPE}_{1}$} & \multirow{2}{*}{$\begin{array}{c}R_{p,} \\
\mathrm{Ohm} \cdot \mathrm{cm}^{2}\end{array}$} & \multicolumn{2}{c|}{$\mathrm{CPE}_{2}$} & \multirow{2}{*}{$\begin{array}{l}R_{1}, \\
\mathrm{Ohm} \cdot \mathrm{cm}^{2}\end{array}$} & $\begin{array}{c}C_{\delta}, \\
\mathrm{F} / \mathrm{cm}^{2}\end{array}$ & $\begin{array}{c}R_{2}, \\
\mathrm{Ohm} \cdot \mathrm{cm}^{2}\end{array}$ \\
\cline { 5 - 7 } & $\begin{array}{c}Y_{1} \\
\text { Samples }\end{array}$ & $n_{1}$ & & $\begin{array}{c}Y_{2}, \\
\mathrm{Cm} \cdot \mathrm{s}^{0.5} / \mathrm{cm}^{2}\end{array}$ & $n_{2}$ & & & \\
\hline $\mathrm{GaSe}$ & - & - & - & - & - & $2.4 \cdot 10^{5}$ & $9.3 \cdot 10^{-12}$ & $1.6 \cdot 10^{8}$ \\
\hline $\mathrm{H}_{0.07} \mathrm{GaSe}$ & $3.52 \cdot 10^{-11}$ & 0.92 & $6.1 \cdot 10^{6}$ & $4.49 \cdot 10^{-8}$ & 0.21 & - & - & - \\
\hline $\mathrm{H}_{0.14} \mathrm{GaSe}$ & $2.4 \cdot 10^{-8}$ & 0.05 & 0.16 & $2.95 \cdot 10^{-11}$ & 0.9 & - & - & - \\
\hline
\end{tabular}



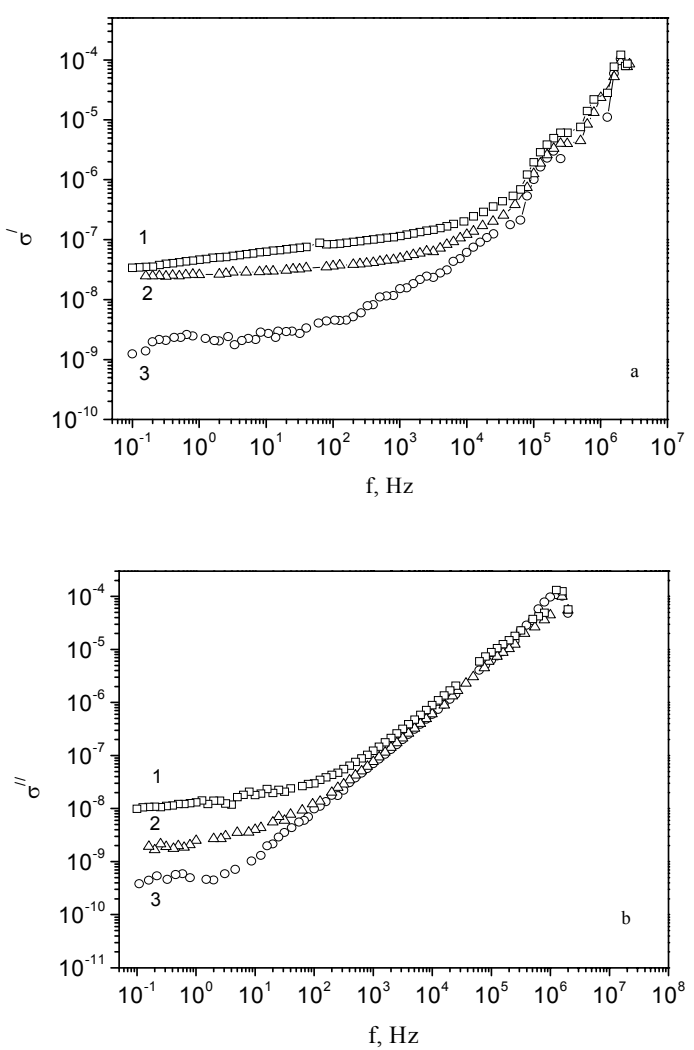

Fig. 3. Frequency dependences of the real $\sigma^{\prime}(a)$ and imaginary $\sigma^{\prime \prime}(b)$ parts of the conductivity of $\mathrm{GaSe}, \mathrm{H}_{0.07} \mathrm{GaSe}$, and $\mathrm{H}_{0.14} \mathrm{GaSe}$ nanocrystals (curves 1 to 3 , respectively).

The low-frequency linear part for $\mathrm{H}_{0.14} \mathrm{GaSe}$ (Fig. 2, curve 3), which most likely defines the electrical properties of hydrogen inserted into pores, is a result of the formation of a space charge nearby the contact electrodes due to the migration of protons of the adsorbed electrolyte to the electrodes. As the relaxation of the processes of ion migration takes place over a long period of time, it prevails in the low-frequency impedance. For the intercalated $\mathrm{H}_{0.07} \mathrm{GaSe}$ and $\mathrm{H}_{0.14} \mathrm{GaSe}$ samples, the obtained values of the relaxation time $\tau$ are $4 \cdot 10^{-4}$ and $2.6 \cdot 10^{-4} \mathrm{~s}$, respectively.

Figure $3 \mathrm{a}, \mathrm{b}$ shows the frequency dependences, $\sigma^{\prime}(v)$ and $\sigma^{\prime \prime}(v)$, of the real and imaginary parts of the conductivity of the initial and intercalated nanocrystalline samples of GaSe (curves 1-3) ( $v$ is the linear frequency). The increase of $\sigma^{\prime}$ and $\sigma^{\prime \prime}$ with frequency can be supposed to be due to two-dimensional defects (stacking faults) creating the potential barriers, which can lead to the dependence of the conductivity on frequency $[10,11]$. The nonlinear behavior of $\sigma^{\prime}(v)$ and $\sigma^{\prime \prime}(v)$ is probably caused by the influence of intergrain boundaries on the processes of charge transfer in the pressed nanocrystalline GaSe samples. The decrease of the real and imaginary parts of the conductivity of the intercalated samples is due to a decrease of the carrier mobility because of a deformation of the nanostructures. During the intercalation, the inserted ions deform the GaSe lattice, which follows from the X-ray investigations on broadening the rocking curves for reflection (004) obtained in the scheme of two-crystal spectrometer.

\section{Conclusion}

It is established that the dielectric spectra of the nanocrystalline samples of $\mathrm{GaSe}, \mathrm{H}_{0.07} \mathrm{GaSe}$, and $\mathrm{H}_{0.14} \mathrm{GaSe}$ correspond to the exponential law of dielectric response. From the carried out measurements of the impedance, we have constructed equivalent circuits which determine electrical characteristics of the investigated crystals, and the increase of the permittivity $\varepsilon_{\infty}$ for the intercalated samples in comparison with that of the initial $\mathrm{GaSe}$ ones is found. We have obtained also the frequency dependences of the real and imaginary parts of the conductivity, whose dispersion is due to the presence of two-dimensional defects.

\section{References}

1. D. O'Hara, Inorganic intercalation compounds / In: Inorganic Compounds. Wiley, London, 1996, p. 172-254.

2. R. Shöllhorn, Intercalation systems as nanostructured functional materials // Chem. Mater. 8(8), p. 1747-1757 (1996).

3. V.M. Kaminskii, Z.D. Kovaluk, M.M. Pyrlya, S.V. Gavrylyuk, V.V. Netyaga, Properties of hydrogenated GaSe crystals // Neorgan. Materialy 41(8), p. 1-3 (2005) (in Russian).

4. L.M. Kulikov, A.A. Semenov-Kobzar, N.B. Kenig, L.G. Akselrud, V.N. Davydov, V.M. Kaminskii, M.M. Pyrlya, V.V. Netyaga, Intercalation of gallium selenide single crystals with hydrogen // Dopovidi Natsional. Akad. Nauk Ukrainy No 1, p. 102-107 (2006) (in Ukrainian).

5. A.V. Zaslonkin, V.M. Kaminskii, Z.D. Kovaluk, I.V. Mintyanskii, M.V. Tovarnitskii, Electrical properties of hydrogenated crystals InSe // Neorgan. Materialy 42 (12), p. 1434-1436 (2006) (in Russian).

6. V.B. Boledzyuk, V.M. Kaminskii, Z.D. Kovaluk, L.M. Kulikov, N.B. Kenig, S.V. Gavrylyuk, V.V. Netyaga, Preparation and physical properties of nanocrystalline gallium and indium selenides // New Technologies 12 (2), p. 90-92 (2006).

7. S.I. Drapak, V.M. Kaminskii, Z.D. Kovaluk, V.V. Netyaga, V.B. Orletskii, Influence of hydrogen on electrical properties of a $\mathrm{Sn}-\mathrm{p}$-InSe contact // Fizyka i Khimiya Tverd. Tila 4 (4), p. 656-658 (2003) (in Ukrainian).

8. Y. Stakhira, O. Flyunt, Ya. Fiala, Low-frequency dielectric spectrum of low-resistive GaSe crystals // Zhurnal Fizychnyh Doslidzhen', 2 (1), p. 136-138 (1998) (in Ukrainian).

9. G.B. Bokiy, Crystallochemistry. Moscow State Univ. Publ., Moscow, 1960 (in Russian).

10. P.T. Oreshkin, Physics of Semiconductors and Dielectrics. Vyssaya Shkola, Moscow, 1977 (in Russian).

11. G.V. Lashkarev, A.I. Dmitriev, A.A. Baida, Z.D. Kovaluk, M.V. Kondrin, A.A. Pronin, Anomalies of static and dynamic conductivity of a many layer InSe crystal // Fizika Tekhnika Poluprovidnikov 37(2), p. 145-150 (2003) (in Russian). 